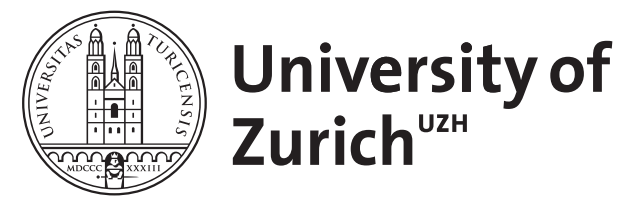

\title{
Well-being and war
}

Frey, Bruno S

\begin{abstract}
Happiness research has dealt with a great number of determinants of well-being but has neglected the effect of war. Wars drastically reduce people's happiness. The large psychic costs of soldiers, the suffering of civilians, and the material destruction are well documented. An important issue for happiness research is how to calculate the forgone well-being of the people killed in war. Wars may also increase happiness by providing shared experiences, raising national pride, and "ennobling" people. "Combat flow" increases an individual soldier's subjective happiness. Deep issues are elicited regarding what type of happiness is legitimate
\end{abstract}

DOI: https://doi.org/10.1007/s12232-012-0146-0

Posted at the Zurich Open Repository and Archive, University of Zurich ZORA URL: https://doi.org/10.5167/uzh-156198

Journal Article

Published Version

Originally published at:

Frey, Bruno S (2012). Well-being and war. International Review of Economics, 59(4):363-375.

DOI: https://doi.org/10.1007/s12232-012-0146-0 


\title{
Well-being and war
}

\author{
Bruno S. Frey
}

Received: 2 November 2011/Accepted: 9 January 2012/Published online: 24 January 2012

(C) Springer-Verlag 2012

\begin{abstract}
Happiness research has dealt with a great number of determinants of well-being but has neglected the effect of war. Wars drastically reduce people's happiness. The large psychic costs of soldiers, the suffering of civilians, and the material destruction are well documented. An important issue for happiness research is how to calculate the forgone well-being of the people killed in war. Wars may also increase happiness by providing shared experiences, raising national pride, and "ennobling" people. "Combat flow" increases an individual soldier's subjective happiness. Deep issues are elicited regarding what type of happiness is legitimate.
\end{abstract}

Keywords Well-being · Happiness · Flow · Military conflict · War · Combat

JEL Classification $\quad \mathrm{D} 60 \cdot \mathrm{F} 50 \cdot \mathrm{H} 56 \cdot \mathrm{I} 31 \cdot \mathrm{N} 44$

\section{Basic issues}

Over the last years, research on happiness has produced great advances. We know much more now about what factors raise people's subjective individual well-being. ${ }^{1}$ Happiness research is perhaps one of the "hottest," and perhaps even revolutionary,

\footnotetext{
1 See, for example, Bruni (2006), Dolan et al. (2008), Easterlin (2002, 2004), Frey (2008), Frey and Stutzer (2002a, 2002b), Graham and Pettinato (2002), Layard (2005), van Praag and Ferrer-i-Carbonell (2004). In line with the literature, the terms (subjective) well-being, happiness, and life satisfaction are used interchangeably.

B. S. Frey $(\bowtie)$

Department of Economics, CREMA, Center for Research in Economics, Management and the Arts, University of Zurich, Wilfriedstrasse 6, 8032 Zurich, Switzerland

e-mail: bruno.frey@econ.uzh.ch

B. S. Frey

University of Warwick, Coventry, UK
} 
developments in recent social science. One of the open questions in well-being research is how military conflict affects subjective individual well-being. The reader may be surprised that this is even an issue at all. Is it not obvious that wars make people unhappy, and even drastically unhappy? I also used to think that everyone accepted that wars reduced the happiness of all the people involved-and I still do. After all, the psychic costs of military combat are well known, and the suffering of the civilian population is evident. Wars cost enormous numbers of human lives. For example, the Second World War resulted in the death of between 50 and 70 million people (Sommerville 2008). Moreover, war hampers economic activity; cities and whole landscapes are devastated, and irrecoverable cultural sites destroyed. ${ }^{2}$

On the other hand, some factors raise the well-being of people experiencing war, at least in retrospect. That wars may be "ennobling" and hence beneficial to warriors has always been a topic in literature. One need only think of the Greek heroes in Homer's Iliad and Odyssey who seemed to enjoy combat. War may also intensify the feeling of solidarity, shared purpose, and national pride in the civilian population.

The research results relating to well-being and war discussed below are revealing but incomplete: There is little systematic and empirically compelling evidence on how military conflict affects happiness. ${ }^{3}$ This paper argues that whether war raises or lowers well-being cannot persuasively be answered without knowing how the people killed in war should be treated in empirical happiness research. ${ }^{4}$ The basic problem can be understood best by considering the following case:

- A person is badly wounded during a war. That person's happiness therefore will strongly decrease. It may recover after some time, but, on average, it will not reach the same level of well-being previously enjoyed. ${ }^{5}$ Even if the person fully recovers, there is still a period of time during which that person experienced a drastic loss of happiness. The happiness indicator for that particular country therefore is lower than it would be without this war incident.

- Compare this to a person killed in war. That person is no longer among the living and cannot be asked about the level of happiness nor can any other measurement technique be applied. ${ }^{6}$ That person's happiness is totally neglected although the fate of dying is clearly worse (in most cases) than surviving even if gravely wounded. The fact that the person was killed does not directly affect the aggregate happiness indicator of the respective country. ${ }^{7}$

\footnotetext{
${ }^{2}$ For a general analysis of the political economy of war, see Coyne and Mathers (2011) or Bradden (2011). The economic costs of war are discussed in Abadie and Gardeazabal (2003), Collier (1999), and Stewart et al. (2001).

3 Frey (2011a) makes a preliminary attempt to summarize the evidence.

4 There are of course other reasons for death, such as malnutrition, natural disasters, traffic accidents, or crime where similar aspects as those considered in the following apply. When part of the population of a country is deported and no longer counts among the present inhabitants, a related issue arises. In this paper, I want to focus on the deadly effects of war in order to highlight the pertinent issues.

5 For adaptation, see Clark et al. (2006).

${ }^{6}$ For example, the Experience Sampling Method, the Day Reconstruction Method, The U-Index, or Brain Imaging (see, e.g., Frey 2008).

7 As argued below, there can be an indirect effect created by the mourning of relatives and friends.
} 
The difference made in the calculation of happiness between the two situations is shocking: The worse situation (death) is reflected in a higher aggregate happiness level than the relatively better situation in which the person survives. What solutions are there to deal with this problem? How should we treat people killed in war who therefore are no longer a living part of society? Two solutions come to mind. The first endeavors to calculate the happiness forgone by the influence of the war. The second seeks to solve the dilemma by definition, by excluding the dead, that is, by only considering the happiness of the living.

Happiness researchers are reluctant to deal with the effect of war activities on happiness for several reasons:

- It is difficult to deal with the many different types of military conflicts ranging from international, national, and all kinds of civil wars.

- Wars have many different and indirect consequences, making it difficult to account for them. Thus, during military conflicts, the health achievement of states decreases, thus negatively affecting the well-being of the population (Iqbal 2006). ${ }^{8}$ In wars, democratic rights are curtailed often leading to authoritarian rule. A reduction in democratic rights is known to impair happiness (Dorn et al. 2005; Frey and Stutzer 2000; Graham and Sukhtankar 2004; Inglehart and Klingemann 2000).

- There is a serious data problem. During a war, surveys are not normally undertaken on how happy people are.

- Causality may be difficult to establish. War not only affects well-being, but well-being also may affect the propensity to engage in war. Unhappy individuals may be more prone to support conflict resolution by military means. The existence and intensity of the two directions of causality can only be isolated if good data (in particular panel data) are available, which is not generally the case for military conflicts and well-being.

The next section of this paper deals with the loss of well-being experienced during military conflicts. The following section discusses the crucial issue of how the well-being forgone of the persons killed is, and should be, treated. Next, I consider in what respect wars may raise the well-being. The last section concludes.

\section{Loss of well-being in war}

\subsection{Psychic costs of military combat}

There is strong evidence that military service in combat strongly reduces the longrun well-being even of the soldiers surviving (see Frey 2011a). Especially after the event, many soldiers are affected by post-traumatic stress disorder, which in the United States showed up in the form of higher rates of crime, violence, and suicide

\footnotetext{
${ }^{8}$ Remember the influenza that broke out during WWI, which killed more people than were killed in combat or during other epidemics and famines or due to a lack of clean water, poor sanitation, and so on that is prevalent during war.
} 
(Rohlfs 2010), as well as in a greater take-up of disability benefits among veterans (Autor et al. 2011). A survey of the evidence on soldiers having served in combat zones found that 26 percent of active soldiers returning from serving in Iraq and Afghanistan experienced lower well-being and suffered from depression, drug and alcohol dependency, homelessness, and suicide (Tanielan and Jaycox 2008).

So far, most of these studies have been descriptive. If at all, they compared these experiences to a civilian comparison group that may have had quite different underlying levels of subjective individual well-being. The draft lottery used in the United States for World War II, the Korean War, and the Vietnam War can be used as an instrument to deal with the endogeneity problem. The corresponding studies (e.g., Angrist et al. 2010; Bedard and Deschenes 2004) reached the same result as the descriptive studies: Draft exposure tends to affect adversely health, and there is an increased risk of suicide, automobile accidents, and mortality due to militaryinduced smoking. As the United States discontinued the lottery draft after the Vietnam War, there is an exogenous variation in combat experience. The US military command now assigns combat duty on the company level and irrespective of personal characteristics of the soldiers. The studies taking this exogenous variation into account found that longer combat service was associated with a greater risk of post-traumatic stress disorder (e.g., Rona et al. 2007). The arguably most refined study for the United States and the wars in Iraq and Afghanistan controls for the mental health of soldiers prior to deployment and exploits the variation in exposure to combat (Cesur et al. 2011). This study found that "combat service is associated with mental health problems ... In particular ... frequent enemy firefight, wounding and injury, and observing the death or wounding of a coalition/ally or non-combatant is associated with a substantial decrease in the risk of suicidal thoughts and post-traumatic stress disorder" (Cesur et al. 2011, 22).

Overall, these studies clearly indicate that engagement in war by soldiers strongly reduces their well-being.

\subsection{Benefits forgone of the killed}

The well-being a person would have enjoyed had that person survived the military conflict can be calculated by exploiting the information contained in econometrically estimated individual happiness functions showing the determinants of individual life satisfaction. For each person killed in a war, it is calculated what the accumulated happiness achieved on average over the remaining expected life years would have been. This procedure assumes that the determinants of individual happiness are captured properly. Moreover, it assumes that the relationship between the determining factors and happiness in the future remains the same as was estimated to be the case over the estimation period of the past.

This procedure is possible but difficult to implement. One would first have to estimate empirically the future happiness based on the characteristics of a person such as that person's age, socioeconomic background, education, health, expected income, and length of life. In a second step, one would have to associate these characteristics to the persons who died in war. This is difficult to do and may result in major mistakes. In particular, if the dead, say young soldiers killed on the 
battlefield, had characteristics not captured by the happiness function estimated, the estimates might be seriously biased. For example, it may well be that the soldiers killed were more optimistic and idealistic than average and therefore happier than persons of otherwise the same characteristics. Personal attributes such as optimism or idealism are not normally part of large-scale happiness studies. As these attributes are positively related to happiness, a standard empirical approach would systematically underestimate the calculated future happiness forgone by the soldiers killed. Military conflict then appears to be less damaging to happiness than it is in reality. In contrast, if mainly pessimistic and materialistic people died during wars, the future well-being forgone by the soldiers killed would be overestimated when an econometrically estimated happiness function is used to calculate aggregate wellbeing.

It should be noted that the aggregate happiness indicator for a country including the well-being forgone of the people killed is no longer related to the population actually living. The more people who died during a war, the more strongly a country's happiness indicator is purely the effect of a calculation rather than of direct observation via representative surveys. Moreover, estimated happiness functions tend to lack credibility when the data basis (the people living) is small relative to the number of people killed during a military conflict. The estimated coefficients of the happiness functions may strongly deviate from what is relevant for the dead, and therefore the calculation of the well-being forgone of the dead is unreliable.

Calculating happiness based on econometric estimates is faced with an additional problem. Such calculations offer a particularly wide scope for governments to influence the happiness indicator in their favor. A government seeking to maximize the happiness of its population has a strong incentive to manipulate the indicator so that it loses its informational content (see Frey 2011b; Frey and Stutzer 2010). The more the aggregate happiness indicator depends on specific choices made when calculating the indicator, the easier it is to manipulate. A malevolent government may even engage in a military conflict intending to kill the unhappy part of the population. The happiness indicator therewith would rise, and based on the calculated happiness indicator the government could claim that it improved the well-being of its population. This is similar to the well-known critique of utilitarianism arguing that the great pleasure of the larger numbers can justify giving small numbers a miserable life (see, e.g., Sen and Williams 1993).

\subsection{Disregarding the well-being of the dead by definition}

Instead of trying to calculate the well-being forgone of the people killed in war, their well-being can be excluded from the happiness count. Aggregate happiness then is simply defined to refer to the living only. If the persons killed on average had the same happiness level as the rest of the population, it would not matter for the average well-being if they were disregarded. However, this is not known; the dead may well be persons with a particularly high or low happiness potential in the future. In that case, the negative effect on happiness of military conflict is under- or overestimated. 
Taking into account the grief, suffering, and mourning of the people who died by parents, children, other relatives, friends, as well as other persons can capture part of the unhappiness created by war. ${ }^{9}$ Empirical research suggests that the psychic costs of losing a relative or friend are substantial (Oswald and Powdthavee 2008). The largest emotional losses occur from the death of a spouse; the second worst loss comes from the death of a child, and the third worst is the death of a parent. Grief continues for many years. It may well be that grief for a departed person is immense to those who remain although the person who passed away may have wanted to die because that person did not expect any happiness in the future.

These results refer to the loss of people under peaceful conditions in present-day developed economies. One can only speculate how much a person killed in a war is mourned. A soldier killed in a war may have wanted to live a long and happy life, but relatives and friends do not mourn the death because they believe that the death was in favor of a "good" or even "holy" cause. Others may even rejoice and increase their level of happiness about what they consider to be a "martyr." In this case, war raises, rather than reduces, happiness.

A major result of empirical happiness research is that people adjust to good and bad experiences (e.g., Frey 2008; Frey and Stutzer 2002a, b). There is a tendency to return to a "set point" of happiness determined by genetic factors. The speed and extent of adjustment varies between areas and persons. The question is whether people are able to adjust to war experiences. The finding that the change in the number of victims (Welsch 2008), rather than their absolute number, reduces wellbeing in civil wars suggests that there is some extent of adaptation to the conditions of conflict. It is possible that in general people do get used to some extent to the horrors of war. The experience that many people die in wars may make the fact that one's son, husband, father, friend, or acquaintance has died in a war more bearable.

How should we deal with this kind of reduction of unhappiness? Should we take war to be less brutal and devastating because people partly adjust to its horror? This is a question relating to all kinds of adjustments. Frederick and Loewenstein (1999, 320) concluded after an extensive and careful study of adaptation: "Would [people] stop wearing seatbelts with the assurance that they would get used to being paralyzed? Would they exploit an embezzlement opportunity knowing that prison wouldn't be all that bad in the long run? We suspect not." (See also Fleurbaey 2009.) In the case of war, it seems that few people would want to engage in military conflict knowing that they could get used to the immense suffering. However, to ignore the process of adaptation is not a convincing solution either because the process of adaptation is based on sound empirical observations.

Few empirical studies have endeavored to capture the effect of war on the happiness of the people left living. ${ }^{10}$ A special type of internal war is terrorism, which targets the civil population. The goal is to create havoc and produce fear (see, e.g., Frey 2004; Sandler and Enders 2004). Frey et al. (2007) employed standard happiness functions for France and Northern Ireland that were affected by terrorism.

\footnotetext{
9 For bereavement, see Stroebe et al. (1993) and Stroebe and Stroebe (1987).

10 The economic costs of war are discussed in Abadie and Gardeazabal (2003), Arunatilake et al. (2001), Bozzoli et al. (2011a, 2011b), Collier (1999), and Stewart et al. (2001).
} 
They were able to show that intensive terrorist activity significantly reduces the life satisfaction of the population. This applied for both the number and victims of terrorist attacks. The calculations revealed that for Northern Ireland the well-being cost from one additional terror victim amounted to about 0.6 percent of income. Welsch (2008) found a similar figure for Israel, Burundi, and Liberia. The attacks of 9/11 on the United States have been shown to have had large psychological costs that may substantially exceed the physical harm (Becker and Rubinstein 2011; Sunstein 2003). The reason is that "dread" constitutes a significant part of the risks from terrorism. Based on eliciting the willingness-to-pay for a lower risk of terrorist attack, Viscusi (2009) found that reductions in deaths from terrorism had a value nearly twice as great as reductions in deaths from natural disasters. A careful study suggested that the effect of a terrorist attack reduced individual well-being beyond the country attacked (Metcalfe et al. 2011). The mental distress produced in the population of the United Kingdom after the 9/11 attacks in the United States is roughly 30 percent of the negative impact of widowhood and almost 20 percent of being unemployed.

In a study of civil wars comprising 44 countries around the year 2000, and using average happiness by country from representative surveys, Welsch (2008) found that the current number of military conflicts significantly and strongly reduced the well-being of the population. The direct effects in terms of suffering, fear, and agony were larger than the indirect effects due to the smaller income associated with civil wars.

\section{War raises well-being}

\section{1 "Happy soldiers" and "combat flow"}

Some people experiencing war find it energizing and even addictive (see, e.g., Hedges 2002). The concept of an "ennobling" war has been present in many cultures, for instance, among Classical Greek soldiers, medieval knights in Europe, and samurais in Japan. Many military conflicts have been termed "good" wars because they were proclaimed to serve a desirable goal. This holds for not only "holy" wars by Christian crusaders and the Jihad by Muslims but also for revolutionary wars in America and Europe (where the levée en masse strengthened this tendency), the two World Wars, and the wars in Vietnam, Iraq, and Afghanistan. People fighting in these wars, and civilians affected by it, may convert the costs of war into psychic benefits.

"Combat flow" is another factor that sometimes raises the happiness of soldiers engaged in the short run. According to Harari (2008, 253): "Such absorption is often reported in combat situations in which it contributes both to the well-being and to the efficiency of soldiers." Harari $(2008,255)$ also documented "addiction to the experience of combat flow" for the Vietnam War. Evidence can easily be found dating back to Homeric Greece and medieval Europe. Tolstoy's (1865-1869 [2006]) War and Peace for the Napoleonic period and Jünger's (1920 [2007]) In 
Stahlgewittern reported many instances of combat flow. ${ }^{11}$ In a careful account of the First World War, Ferguson $(1999,352)$ refers to a "spirit of bonhomie and cheerfulness ... [and] trench humour." He asks whether there is a "Joy of War" (Ferguson 1999, 357), and he concludes: "In the final analysis, this may be the best explanation of all for the continuation of the conflict: Oh! What a lovely war, literally" (Ferguson 1999, 360). He mentions that (some) women also enjoyed war and that soldiers experienced satisfaction by killing, supporting the notion of "combat flow." This also applies to mass murder as committed by German soldiers on the Eastern front during World War II or by American soldiers in My Lai during the War in Vietnam. Based on the protocols of the conversations among German prisoners collected by the British (see Neitzel and Welzer 2011; Tyas 2008): "Den Männern machte es Spass, etwas tun zu können, was sie unter gewöhnlichen Umständen niemals hätten tun dürfen ... Offenbar war das Morden ... für nicht wenige Männer eine kaum widerstehliche Verlockung." 12

It seems that the notion of combat flow even applies to bystanders. In German, there is a term "Schlachtenbummler" that aptly describes the attraction to civilians of viewing soldiers dying in combat and even having a picnic among the dying and wounded soldiers. ${ }^{13}$ It even occurred against explicit orders by the army that civilians continually attended mass murders and encouraged the soldiers killing the innocent victims. These bystanders enjoyed observing the unhappiness of other persons (Neitzel and Welzer 2011).

\subsection{Shared experience}

Persons who have experienced war often refer to a feeling of happiness due to the solidarity emerging and even more importantly due to the common effort and shared purpose (Hedges 2002). War provides a purpose in life otherwise missing to a significant number of people. As a result, war events dominate the internal turmoil within some people and are experienced as a relief. During wars, the number of suicides decreases because the military conflict overrides personal problems.

Another reason why war experiences in retrospect may appear to be positive is due to what can be called "afterglow." ${ }^{14}$ When terrible events happen, people are glad to have survived. They then begin to reconstruct their past in a positive light and look at it as a great experience. This is a special form of remembering.

It may be hypothesized that the type of military conflict and the expectations about its outcome may also influence how happiness is affected. When young men are drafted by force, the conflict may be experienced as positive as long as people expect to be on the winning side. As soon as this expectation turns negative, the

\footnotetext{
11 See, in general, Bourke (1999), Neitzel and Hohrath (2008), and Waller (2002); for World War I, see Kramer (2007); for World War II, see Lüdtke (1992) and Linderman (1999).

12 Translated by the author as, "The men had fun doing something which they would never be allowed to do under normal conditions ... Obviously for not few men murdering ... had an almost irresistible attraction."

13 In English, the term "camp follower" is used only in sports.

14 I owe this expression and the account to Richard Layard.
} 
casualties and other burdens of war are likely to be felt in a more negative way. This effect is likely to be experienced more by the civilian population than by professional soldiers.

\subsection{How to treat happiness in war}

The various instances of happiness in war can be dismissed as unacceptable for moral reasons. Harsanyi (1993) explicitly argued, "sadistic and malicious" pleasures need to be excluded from the social welfare function (see, for a similar argument, Sen 2009 and much earlier Mill 1869). With respect to military conflict, Harari $(2008,260)$ states, "It would be dangerously easy to justify any war waged by an army of happy soldiers high on combat flow." Such a position can be attributed to Socrates, Plato, and Aristotle with their notion of "eudaimonia" and corresponds to much of classical Greek philosophy (McMahon 2006; Nussbaum 2008).

To disregard the forms of happiness experienced in war is, however, a drastic solution as it does not take into account the well-documented feelings of happiness because they are illegitimate. It is difficult to consider positively valued experiences such as shared purpose, solidarity, trust, and friendship, as well as national pride to be unacceptable. What is certainly needed is to reconsider the concept of well-being employed. Sensual pleasures, such as combat flow, are not compatible with the summum bonum of "true" happiness (see, e.g., Harari 2008).

\section{Concluding remarks}

In view of the many wars regularly taking place all over the world and the large number of casualties produced among soldiers and civilians, it is surprising that the effect of military conflict on individual well-being has had so little research. A crucial issue is how happiness research should treat people killed in military conflicts. The present procedure in this research (as elsewhere in welfare economics) is to disregard the potential future happiness that the deceased would have enjoyed. Instead, only the well-being of the living is taken into account. This procedure is questionable. It means that the suffering of people wounded but still living and possibly even enjoying some measure of happiness is considered. In contrast, if the same person had died-a worse fate-it is not counted at all.

An alternative way is to calculate the well-being forgone by the people killed in war. This would be difficult but not impossible to do. The estimates certainly can be considered only a vague approximation. Moreover, if a substantial share of the population died in a war, the aggregate happiness indicator relies on a doubtful foundation. The econometric results then are no longer based on direct subjective surveys on well-being but largely are the result of a transfer of estimates from persons still living to those who died often a considerable time in the past.

The empirical literature on the effects of military conflict on happiness is scarce. There are views emphasizing the benefits of war to individuals by raising the shared feeling of solidarity and mutual support. "Combat flow" has been identified as 
increasing soldiers' subjective well-being under some conditions and in the short run. Moreover, there may be an afterglow glorifying the war experience. At the same time, an extensive literature has evolved documenting the large psychic costs of soldiers engaged in military combat, in particular when confronted with the wounded, injured, and dying. Post-traumatic stress disorder results in, among other things, higher rates of suicide, thus revealing a drastic fall in happiness. In addition, there are studies suggesting that terrorism and civil wars significantly reduce happiness.

The existing empirical literature at this point does not allow one to conclude firmly that war (strongly) reduces individual well-being. However, I am convinced that military conflict has dreadful consequences and should be avoided, but I must nevertheless accept that there are positive effects of war on happiness. One can argue that the concept of pleasure or happiness as a simple sensation composed of variations along a unique quantitative dimension used in econometric studies is faulty (see Nussbaum 2008). Psychologists and economists (see Kahneman and Krueger 2006) have borrowed the concept from Bentham (1789), but philosophers like Plato, Aristotle, or James Stuart Mill entertained a much richer idea called "eudaimonia," which refers to a general and multidimensional concept of human flourishing rather than a simple "hedonic flow." According to Nussbaum (2008, 84-85), "Bentham cannot be said to have developed anything like a convincing account of ... happiness ... Modern philosophical discussion ... [therefore] follows Aristotle and Mill." Although this criticism should be taken seriously, the advantages of a one-dimensional scale of subjective individual well-being should not be overlooked. As has been shown (see, e.g., Frey 2008; Frey and Stutzer 2002a), these indicators correlate highly with reasonable objective indicators such as laughing, optimism, social integration, and suicide, and the respective estimates provide us with useful insights about the determinants of happiness. This also can be expected to be the case if military conflicts are more extensively studied as (one of the many) determinants of subjective well-being.

The discussion reveals that analyzing the effect of war on happiness elicits deep issues going beyond one particular academic discipline, in particular far beyond economics. Only serious interdisciplinary exchange and discussion can help us to resolve these issues. The basic questions are, of course, not new but have a long history. They refer not only to deadly conflicts but also to the loss of life due to other events such as natural disasters and traffic accidents. However, they appear in a particularly striking way when studying how war affects happiness. What is new is the emphasis on empirical evidence - an aspect generally absent in the respective philosophical discourse. To look at the effects of military conflict on individual well-being by econometrically analyzing data may help us to reconsider some aspects and to see them in a new light. It may also contribute to better understanding what "subjective well-being" or "happiness" is, particularly in times of war.

Acknowledgments I am grateful to helpful remarks to Richard Layard, Maik Meusel, Margit Osterloh, Alois Stutzer, Lasse Steiner, and the discussants at the Happiness Conference at Bicocca University June 8-10, 2011. 


\section{References}

Abadie A, Gardeazabal J (2003) The economic costs of conflict. A case study of the basque country. Am Econ Rev 93:113-132

Angrist JD, Chen SH, Frandsen BR (2010) Did Vietnam veterans get sicker in the 1990s? The complicated effects of military service on self-reported health. J Public Econ 94:824-837

Arunatilake N, Jayasuriya S, Kelegama S (2001) The economic costs of the war in Sri Lanka. World Dev 51:168-183

Autor D, Duggan MG, Lyle DS (2011) Battle scars? The puzzling decline in employment and rise in disability receipt among Vietnam era veterans. Am Econ Rev 101(3):339-344

Becker GS, Rubinstein Y (2011) Fear and the response to terrorism: an economic analysis. Unpublished paper, Department of Economics, University of Chicago. Retrieved from http://www.econ. brown.edu/fac/yona_rubinstein/Research/Working\%20Papers/BR_FEB_2011.pdf

Bedard K, Deschenes O (2004) The long-term impact of military service on health: evidence from World War II and the Korean War. Am Econ Rev 96(1):176-194

Bentham J (1789 [1996]) An introduction to the principles of morals and legislation. Clarendon Press, London

Bourke J (1999) An intimate history of killing. Granta, London

Bozzoli C, Brück T, de Groot OJ (2011a) How many bucks in a bang: calculating the global costs of conflict. In: Garfinkel M, Skaperdas G (eds) Oxford handbook of peace and conflict, forthcoming. Institute of Development Studies, Brighton, UK. Retrieved from http://www.socsci.uci.edu/ $\sim$ mrgarfin/OUP

Bozzoli C, Brück T, de Groot OJ (2011b) The global economic costs of conflict. GEEC Project Paper 3/2011. Retrieved from http://www.diw.de/gecc

Bradden DL (2011) Handbook on the economics of conflict. Edward Elgar, Cheltenham

Bruni L (2006) Civil happiness: economics and human flourishing in historical perspective. Routledge, Abington

Cesur R, Sabia JJ, Tekin E (2011) The psychological costs of war: military combat and mental health. NBER Working Paper 16927

Clark A, Diener E, Georgellis Y, and Lucas R (2006) Lags and leads in life satisfaction: a test of the baseline hypothesis. Working paper, CNRS and DELTA-Fédération Jourdan

Collier P (1999) On the economic consequences of civil war. Oxf Econ Papers 51: 168-183. http://dx.doi.org/10.1093/oep/51.1.168

Coyne CC, Mathers RL (2011) The handbook on the political economy of war. Edward Elgar, Cheltenham

Dolan P, Peasgood T, White M (2008) Do we really know what makes us happy? A review of the economic literature on the factors associated with subjective well-being. J Econ Psychol 29:94-122

Dorn D, Fischer JAV, Kirchgässner G, Sousa-Poza A (2005) Is it culture or democracy? The impact of democracy and culture on happiness. Soc Indic Res 82:505-526

Easterlin R (2002) Happiness in economics. Edward Elgar, Cheltenham

Easterlin R (2004) Explaining happiness. Proc Natl Acad Sci 100:1176-1183

Ferguson N (1999) The pity of war. Basic Books, New York

Fleurbaey M (2009) Beyond GDP: The quest for a measure of social welfare. J Econ Lit 47:1029-1075

Frederick S, Loewenstein G (1999) Hedonic adaption. In: Diener E, Kahnemann D, Schwarz N (eds) Well-being: the foundations of hedonic psychology. Russell Sage Foundation, New York

Frey BS (2004) Dealing with terrorism: stick or carrot?. Edward Elgar, Cheltenham

Frey BS (2008) Happiness: a revolution in economics. The MIT Press, Cambridge

Frey BS (2011a) Peace, war and happiness. bruder klaus as well-being facilitator. Int J Well-being 1(2), forthcoming. Retrieved from http://www.internationaljournalofwellbeing.org/ijow/index.php/ijow/ issue/view/4

Frey BS (2011b) Tullock challenges: happiness. Revolut Democr Public Choice 148(3-4):269-281. doi: $10.1007 / \mathrm{s} 11127-011-9821-\mathrm{z}$

Frey BS, Stutzer A (2000) Happiness, economy and institutions. Econ J 110:918-938

Frey BS, Stutzer A (2002a) Happiness and economics. Princeton University Press, Princeton and Oxford

Frey BS, Stutzer A (2002b) What can economists learn from happiness research? J Econ Lit 40(2):402-435

Frey BS, Stutzer A (2010) Happiness and public choice. Public Choice 144:557-573 
Frey BS, Luechinger S, Stutzer A (2007) Calculating tragedy: assessing the costs of terrorism. J Econ Surv 21:1-24

Graham C, Pettinato S (2002) Frustrated achievers: winners, losers and subjective well-being in new market economies. J Dev Stud 38(4):100-140

Graham C, Sukhtankar S (2004) Does economic crises reduce support for markets and democracy in Latin America? Some evidence from surveys of public opinion and well-being. J Lat Am Stud 36:349-377

Harari YN (2008) Combat flow: military, political, and ethical dimensions of subjective well-being in war. Rev Gen Psychol 12:253-264

Harsanyi JC (1993) Morality and the theory of rational behavior. In: Sen A, Williams B (eds) Utilitarianism and Beyond. Cambridge University Press, Cambridge, pp 39-62

Hedges C (2002) War is a force that gives us meaning. Anchor Books, New York

Inglehart R, Klingemann H-D (2000) Genes, culture and happiness. MIT Press, Cambridge

Iqbal Z (2006) Health and human security: the public health impact of violent conflict. Int Stud Q 50:631-649

Jünger E (1920 [2007]) In Stahlgewittern. Klett-Cotta, Stuttgart

Kahneman D, Krueger AB (2006) Developments in the measurement of subjective well-being. J Econ Perspect 20:3-24

Kramer A (2007) Dynamic of destruction: culture and mass killing in the First World War. Oxford University Press, Oxford

Layard R (2005) Happiness: lessons from a new science. Penguin Press, New York

Linderman GF (1999) The world within war. America's combat experience in World War II. Harvard University Press, Cambridge

Lüdtke A (1992) The appeal of exterminating "others". German workers and the limits of resistance. J Mod Hist 64:S46-S67

McMahon DM (2006) Happiness: a history. Atlantic Monthly Press, New York

Metcalfe R, Ponthavee N, Dolan P (2011) Destruction and distress. Using a quasi-experiment to show the effects of the September 11 attacks on mental well-being in the United Kingdom. Econ J 121:F81F103

Mill JS (1869) The subjection of women. D. Appleton Co., New York

Neitzel S, Hohrath D (eds) (2008) Kriegsgreuel. Die Entgrenzung der Gewalt in kriegerischen Konflikten vom Mittelalter bis ins 20. Jahrhundert. Schöningh, Paderborn

Neitzel S, Welzer H (2011) Soldaten. Protokolle von Kämpfen, Töten und Sterben. S. Fischer, Frankfurt/M

Nussbaum MC (2008) Who is the happy warrior? Philosophy poses questions to psychology. J Leg Stud 37:S81-S113

Oswald AJ, Powdthavee N (2008) Death, happiness, and the calculation of compensatory damages. J Leg Stud 37:217-252

Rohlfs C (2010) Does combat exposure make you a more violent or criminal person? Evidence from the Vietnam draft. J Hum Res 45(2):271-300

Rona RJ, Hull L, Earnshaw M, Wesseley S (2007) Mental health consequences of overstretch in the UK armed forces: first phase of a cohort study. British Med J 335(7620):603-610

Sandler T, Enders W (2004) An economic perspective on transitional terrorism. Eur J Political Econ 20(2):301-316

Sen A (2009) The idea of justice. Penguin, London

Sen A, Williams B (1993) Introduction. In: Sen A, Williams B (eds) Utilitarianism and beyond. Cambridge University Press, Cambridge

Sommerville D (2008) The complete illustrated history of world war two. An authoritative account of the deadliest conflict in human history. Lorenz Books, London

Stewart F, Huang C, Wang M (2001) International wars: an empirical overview of the economic and social consequences. In: FitzGerald V, Stewart S (eds) War and underdevelopment. Oxford University Press, Oxford, pp 67-103

Stroebe M, Stroebe W (1987) Bereavement and health: The psychological and physical consequences of partner loss. Cambridge University Press, Cambridge

Stroebe MS, Hansson RO, Stroebe W (1993) Contemporary themes and controversies in bereavement research. In: Stroebe MS, Stroebe W, Hansson RO (eds) Handbook of bereavement: theory, research, and intervention. Cambridge University Press, Cambridge, pp 457-476

Sunstein CR (2003) Terrorism and probability neglect. J Risk Uncertain 26:121-136 
Tanielan T, Jaycox LH (eds) (2008) Invisible wounds of war: psychological and cognitive injuries, their consequences, and services to assist recovery. Rand Corporation. Retrieved from http://www.rand. org/pubs/monographs/2008/RAND_MG720.pdf

Tolstoy LN (1865-69/2006) War and peace. Penguin, London

Tyas S (2008) Allied intelligence agencies and the holocaust: information acquired from german prisoners of war. Holocaust Genocide Stud 22:1-24

Van Praag B, Ferrer-i-Carbonell A (2004) Happiness quantified: a satisfaction calculus approach. Oxford University Press, New York

Viscusi WK (2009) Valuing risks of death from terrorism and natural disasters. Working Paper No. 09-08, Law and Economics, Vanderbilt University Law School

Waller J (2002) Becoming evil. How ordinary people commit genocide and mass killing. Oxford University Press, Oxford

Welsch H (2008) The social cost of civil conflict. Kyklos 61:320-340 